\title{
Prevalence of overweight/obesity and associated factors in adults in Erbil, Iraq: A household survey
}

\section{Sherzad A. Shabu*}

\begin{abstract}
Background and objective: Overweight and obesity are important risk factors for the development of some important chronic diseases and are, thus, considered leading risks for deaths. This study aimed to find out the prevalence of overweight and obesity with their associated risk factors in the adult population.

Methods: A household cross-sectional survey was carried out in Erbil city, Iraq from April to June 2017. The study involved 1480 adults selected through a multi-stage sampling method. A specially designed questionnaire was used to collect socio-demographic and other relevant data from the participants through direct interview. The height and weight were measured for all participants.
\end{abstract}

Results: The overall prevalence of overweight and obesity was $74.3 \%$ (33.4\% overweight and $40.9 \%$ obese). There was a statistically significant association between being overweight and obese and older age groups, female gender, being married, low level of education, unemployment, not smoking, and not performing physical exercises. Following a multivariate analysis age $(\mathrm{OR}=2.36,95 \% \mathrm{Cl}=1.60-3.49)$, female gender $(\mathrm{OR}=2.17$, $95 \% \mathrm{Cl}=1.53-3.08)$, and married status $(\mathrm{OR}=1.87,95 \% \mathrm{Cl}=1.20-2.90)$ were found to be statistically significant factors associated with overweight and obesity.

Conclusion: The prevalence of overweight and obesity in the adult population in Erbil city is very high. This alarming epidemic requires serious consideration of the health policymakers and public health specialists to plan effective and preventive and control measures. Health education is one way through which people's awareness of this important health issue could be raised.

Keywords: Overweight and obesity; Prevalence; Household survey; Risk factors.

\section{Introduction}

Overweight and obesity involve abnormal or excessive fat accumulation and are considered a risk to health. A common measure of obesity is the Body Mass Index (BMI), which is obtained from dividing the weight of the individual (in kilograms) on the square of his or her height (in meters). A BMI equal or more than 25 is considered overweight, while a BMI of 30 and above is considered obese. A weight that is higher than what is regarded as a healthy weight for a given height is considered overweight or obese. ${ }^{1}$ Globally, overweight and obesity are considered to be the 5th leading risk for deaths, ${ }^{2}$ with an estimation of 2.8 million annual deaths among adults. ${ }^{3}$
Overweight and obesity are wellrecognized risk factors for increasing the prevalence of different chronic diseases, including cardiovascular diseases, diabetes, and cancer. The estimated number of overweight adults in the world, according to a recent report, was 2.1 billion in 2013, compared to 857 million in $1980 .^{4}$ According to $\mathrm{WHO}$, the prevalence of obesity worldwide has nearly tripled since 1975. In 2016, the prevalence of overweight and obesity in adults aging eighteen years and over was 39\% and $13 \%$ respectively. Overweight and obesity are responsible for more deaths than underweight in countries where most of the overweight and obese people live. ${ }^{5}$

* Department of Community Medicine, College of Medicine, Hawler Medical University, Erbil, I raq. 
A study conducted in the USA in 20112012 revealed that $34.9 \%$ of adults aging 20 years and more are obese. ${ }^{5}$ According to a WHO working document in Eastern Mediterranean Region, data about adults from 16 different countries of the region showed very high rates of overweight/ obesity in Kuwait, Egypt, United Arab Emirates, Saudi Arabia, Jordan, and Bahrain. The prevalence of overweight/ obesity in these countries ranged from $69 \%$ to $77 \%$ in men and from $74 \%$ to $86 \%$ in women. ${ }^{6} \mathrm{~A}$ study conducted in China in 2015 revealed an overweight/obesity prevalence of $69.8 \%$, increasing with age till the age of 60 and declining later on. ${ }^{7}$ Primary or idiopathic obesity is the most common type of obesity, and it needs to be distinguished from the secondary obesity, which could be due to endocrine disease, genetic disorders, central nervous system lesions, or other causes. ${ }^{8}$ With the increasing trends of overweight and obesity in developing countries, and because of the limited research from Iraqi Kurdistan Region on this important topic, we thought that this study would improve the existing knowledge about the prevalence of overweight and obesity and their associated risk factors. This study aimed to find out the prevalence of overweight and obesity and identify the associated risk factors among the adult population in Erbil city, Iraqi Kurdistan Region.

\section{Methods}

A community-based cross-sectional survey, based on household visits was carried out in Erbil city, Iraq during the period April to June 2017. A multi-stage sampling method was used to select the study participants. At first, Erbil city was divided into 20 quarters based on the administrative map of the city. Later on, a systematic random sampling method was used to collect 30 households per each quarter. The first household in each quarter was selected randomly. The study population included all the adult inhabitants of these households, aged 18 years and more. Data collection was done through direct interview using a special questionnaire designed for this purpose. The questionnaire included personal and socio-demographic information such as age, gender, marital status, educational level, and occupation. It also included questions on smoking, alcohol consumption, diet, salt intake and performing physical exercise. The weight of the study participants was measured using UNICEF calibrated digital scale (Seca 890) with the participants were wearing light clothes and put off their shoes. An average of one kilogram was estimated to be deducted from the participants' weight to replace the weight of their clothes. The height of participants was measured in centimeters using a portable tape measure which was fixed on the wall. Participants were asked to stand bare feet with their backs against the wall with their heels touching the wall. Epi-info was used to calculate the required sample size. Assuming that the prevalence of overweight/obesity in Erbil city population is similar to the $68.7 \%$ reported in a previous study conducted in the city, ${ }^{9}$ we found that a sample size of 1473 was sufficient to achieve a $95 \%$ confidence interval for the prevalence $( \pm 2.5 \%)$ in this population. The sample was increased to 1500 to accommodate for non-response. Ethical approval was obtained from the Research Ethics Committee of the College of Medicine, Hawler Medical University. Approval was also obtained from Erbil Governor and Erbil Mayer offices to access the different quarters in Erbil city. Verbally informed consents were obtained from the participants who were assured about the anonymity of the study. The statistical package for the social sciences (version 19) was used for data entry and analysis. A $p$-value equal or less than 0.05 was considered as statistically significant. The multivariate analysis was based on binary logistic regression to adjust for and examine the independent effects of possible covariates. Odds ratios (ORs) with their 95\% confidence intervals $(\mathrm{Cl})$ were 
calculated. ORs were estimated to years and older constituted about a quarter measure the strength of the associations while 95\% confidence intervals and the $p$-values were estimated for significance testing.

\section{Results}

From 600 visited households, 1480 adults (363 males and 1117 females) were interviewed in this study. Age group 60 of the participants, with an overall mean \pm SD age of $46.4 \pm 16.3$ years, and a minimum age of 20 and a maximum one of 92 years. The participants were mainly housewives $(62.6 \%)$ followed by government office-based $(20.1 \%)$. The participants were mainly $(45.1 \%)$ illiterates and most of them were married $(90.1 \%)$ as shown in Table 1.

Table 1: The socio-demographic characteristics of the studied sample.

\begin{tabular}{|c|c|c|}
\hline Variable & Frequency & Percentage \\
\hline \multicolumn{3}{|l|}{ Age } \\
\hline $20-29$ & 251 & $(17.0)$ \\
\hline $30-39$ & 336 & $(22.7)$ \\
\hline $40-49$ & 307 & $(20.7)$ \\
\hline $50-59$ & 211 & $(14.3)$ \\
\hline $60+$ & 375 & $(25.3)$ \\
\hline \multicolumn{3}{|l|}{ Gender } \\
\hline Male & 363 & $(24.5)$ \\
\hline Female & 1117 & $(75.5)$ \\
\hline \multicolumn{3}{|l|}{ Occupation } \\
\hline Government office-based & 298 & $(20.1)$ \\
\hline Government labor-based & 3 & $(0.2)$ \\
\hline Private office-based & 37 & $(2.5$ \\
\hline Private labor-based & 2 & $(0.1)$ \\
\hline Housewife & 926 & $(62.6)$ \\
\hline Student & 35 & $(2.4)$ \\
\hline None & 179 & $(12.1)$ \\
\hline \multicolumn{3}{|l|}{ Education } \\
\hline Illiterate & 667 & $(45.1)$ \\
\hline Primary & 339 & $(22.9)$ \\
\hline Secondary & 170 & $(11.5)$ \\
\hline Tertiary & 304 & $(20.6)$ \\
\hline \multicolumn{3}{|l|}{ Marital status } \\
\hline Single & 142 & $(9.6)$ \\
\hline Married & 1334 & $(90.1)$ \\
\hline Divorced & 2 & $(0.1)$ \\
\hline Widow & 2 & $(0.1)$ \\
\hline
\end{tabular}


Of 1480 study participants, $494(33.4 \%)$ as shown in Table 2. A statistically were overweight, and $604(40.8 \%)$ were obese. Most of the participants (93\%) declared having an active lifestyle, but more than $94 \%$ of them were not practicing physical exercises. The majority of the participants were not smokers $(92 \%)$, significant association was found between being overweight/obese and older age groups, female, married, low educational level, unemployment, nonsmokers and not performing physical exercises, as shown in Table 3.

Table 2: Dietary and other lifestyle characteristics of the study participants.

\begin{tabular}{lcc}
\hline Characteristic & Frequency & Percent \\
\hline Weight status $(\mathbf{n = 1 4 7 7 )}$ & 3 & $(0.2)$ \\
Underweight & 379 & $(25.6)$ \\
Normal weight & 494 & $(33.4)$ \\
Overweight & 604 & $(40.8)$ \\
Obese & & \\
Practicing exercise $(\mathbf{n = 1 4 8 0 )}$ & 1396 & $(94.3)$ \\
No & 84 & $(5.7)$ \\
Yes & & \\
Smoking $(\mathbf{n = 1 4 8 0 )}$ & 1369 & $(92.5)$ \\
No & 111 & $(7.5)$ \\
Yes & & \\
\hline
\end{tabular}

Table 3: Association between weight status and other variables.

\begin{tabular}{|c|c|c|c|c|}
\hline Variables & $\begin{array}{c}\text { Normal weight } \\
\text { No. (\%) }\end{array}$ & $\begin{array}{c}\text { Weight status } \\
\text { Overweight/obese } \\
\text { No. (\%) }\end{array}$ & $\begin{array}{c}\text { Total } \\
\text { No. (\%) }\end{array}$ & $P$ value \\
\hline \multicolumn{5}{|l|}{ Age groups } \\
\hline $20-29$ & $134(53)$ & $117(47)$ & $251(100)$ & \multirow{5}{*}{$<0.001$} \\
\hline $30-39$ & $97(29)$ & $237(71)$ & $334(100)$ & \\
\hline $40-49$ & $51(17)$ & $256(83)$ & $307(100)$ & \\
\hline $50-59$ & $30(14)$ & $180(86)$ & $210(100)$ & \\
\hline $60+$ & $67(18)$ & $308(82)$ & $375(100)$ & \\
\hline \multicolumn{5}{|l|}{ Gender } \\
\hline Male & $141(39)$ & $222(61)$ & $363(100)$ & \multirow[b]{2}{*}{$<0.001$} \\
\hline Female & $238(21)$ & 876 (79) & $1114(100)$ & \\
\hline \multicolumn{5}{|c|}{ Marital status } \\
\hline Single & $85(60)$ & $57(40)$ & $142(100)$ & \multirow[b]{2}{*}{$<0.001$} \\
\hline Ever married & $294(22)$ & $1041(78)$ & $1335(100)$ & \\
\hline \multicolumn{5}{|c|}{ Education level } \\
\hline Illiterate & $122(18)$ & $544(82)$ & $666(100)$ & \multirow{4}{*}{$<0.001$} \\
\hline Primary & $86(26)$ & $251(74)$ & $337(100)$ & \\
\hline Secondary & $60(35)$ & $110(65)$ & $170(100)$ & \\
\hline Tertiary & $111(37)$ & $193(63)$ & $304(100)$ & \\
\hline \multicolumn{5}{|l|}{ Employment } \\
\hline No & $265(23)$ & $872(77)$ & $1137(100)$ & \multirow[t]{2}{*}{$<0.001$} \\
\hline Yes & $114(34)$ & $226(66)$ & $340(100)$ & \\
\hline \multicolumn{5}{|l|}{ Smoking } \\
\hline No & $337(25)$ & $1029(75)$ & 1366(100) & \\
\hline Yes & $42(38)$ & $69(62)$ & 111 (100) & $<0.001$ \\
\hline \multicolumn{5}{|c|}{ Performing exercise } \\
\hline No & $340(24)$ & $1054(76)$ & $1394(100)$ & \multirow[t]{2}{*}{$<0.001$} \\
\hline Yes & $39(47)$ & $44(53)$ & $83(100)$ & \\
\hline
\end{tabular}


The multivariate analysis of the studied variables showed age (OR 2.36, 95\% Cl 1.60-3.49), female (OR 2.17, 95\% Cl 1.53-3.08) and ever married (OR 1.87, $95 \% \mathrm{Cl} 1.20-2.90)$ as statistically significant factors associated with overweight/obesity as its shown in Table 4.

\section{Discussion}

This study revealed that the overall prevalence of overweight and obesity among Erbil adults is $74.3 \%$, with a prevalence of $33.4 \%$ for overweight and $40.9 \%$ for obesity. These results were higher compared to those of a study conducted in Erbil on the prevalence of metabolic syndrome, which revealed an overall prevalence of $68.7 \%$, and a $35 \%$ prevalence of obesity. ${ }^{9}$ They are also much higher than those of a study conducted in Basrah which revealed a $55.1 \%$ prevalence of overweight and obesity. ${ }^{10}$ They were also much higher than those of an Iranian study, which revealed a $21.7 \%$ prevalence of obesity. ${ }^{11}$ The current study revealed a significantly higher prevalence of overweight/obesity among the older age groups. These results are consistent with those reported by a study conducted in Malta which showed that those aged 55-64

Table 4: Multivariate analysis of factors associated with overweight/obesity.

\begin{tabular}{|c|c|c|c|c|}
\hline \multirow{2}{*}{ Variable } & \multirow{2}{*}{ OR } & \multicolumn{2}{|c|}{$95 \% \mathrm{Cl}$} & \multirow{2}{*}{$P$ value } \\
\hline & & Lower & Upper & \\
\hline \multicolumn{5}{|l|}{ Age in years } \\
\hline $20-29$ & Ref & & & \\
\hline $30-39$ & 2.36 & 1.60 & 3.49 & $<0.001$ \\
\hline $40-49$ & 4.63 & 2.98 & 7.19 & $<0.001$ \\
\hline $50-59$ & 6.42 & 3.84 & 10.73 & $<0.001$ \\
\hline$\geq 60$ & 4.10 & 2.66 & 6.30 & $<0.001$ \\
\hline \multicolumn{5}{|l|}{ Gender } \\
\hline Male & Ref & & & \\
\hline Female & 2.17 & 1.53 & 3.08 & $<0.001$ \\
\hline \multicolumn{5}{|l|}{ Marital status } \\
\hline Single & Ref & & & \\
\hline Ever married & 1.87 & 1.20 & 2.90 & 0.01 \\
\hline \multicolumn{5}{|l|}{ Employment } \\
\hline Employed & Ref & & & \\
\hline Non-Employed & 1.16 & 0.76 & 1.77 & 0.49 \\
\hline \multicolumn{5}{|l|}{ Education } \\
\hline Tertiary & Ref & & & \\
\hline Illiterate & 1.09 & 0.67 & 1.77 & 0.73 \\
\hline Primary & 1.00 & 0.62 & 1.61 & 0.99 \\
\hline Secondary & 1.05 & 0.66 & 1.66 & 0.85 \\
\hline \multicolumn{5}{|c|}{ Practicing exercise } \\
\hline Regular exercise & Ref & & & \\
\hline No exercise & 1.42 & 0.84 & 2.39 & 0.19 \\
\hline \multicolumn{5}{|l|}{ Smoking } \\
\hline Smokers & Ref & & & \\
\hline Non-smokers & 0.88 & 0.53 & 1.47 & 0.63 \\
\hline
\end{tabular}


years old exhibiting the highest prevalence of overweight for both genders. ${ }^{12}$ A study conducted on Chinese adults also revealed that the prevalence of overweight increased with age up to the age of 60 , and it declined after that. ${ }^{7}$ This can be due to having a more sedentary lifestyle and performing less physical exercises while getting older. This study revealed that the prevalence of overweight/obesity is significantly higher among females compared to males, $79 \%$, and $61 \%$, respectively. These results agree with those of a study conducted in Iran, which revealed a prevalence of $63.9 \%$ and $49.7 \%$ among females and males, respectively. ${ }^{13}$ They also agree with those of a study from Basrah that revealed a prevalence of $54.7 \%$ in females and $45.3 \%$ in males. ${ }^{10}$ This difference can be attributed to the fact that females have a more sedentary lifestyle as the majority of female participants in our study were housewives. On the contrary, a study conducted on Chinese adults revealed a significant increase in BMI, waist circumference and hip circumference among males compared to female. ${ }^{7}$ A significant statistical association was found between being overweight or obese and low educational level of the participants, $82 \%$ prevalence among illiterate participants compared to $74 \%$ of the primary education level, $65 \%$ and $63 \%$ among secondary and tertiary education levels respectively. This could be due to the low awareness level of the illiterate people about the health consequences of obesity since health awareness is expected to rise with the individual's educational level. These results were consistent with those of the Basrah's study, which revealed a significant increase in the rates of overweight and obesity among illiterates (34\% and 35.3\%) compared to those having a higher education level than secondary school $(17.8 \%$ and $17.6 \%) .{ }^{10}$ According to our study, higher $(77 \%)$ prevalence of overweight/obesity were among unemployed adults compared to the employed ones (66\%), and these were statistically significant. The study conducted in Nepal and Bangladesh showed a higher prevalence of overweight and obesity among employed women in Nepal, but a lower prevalence among employed women in Bangladesh. $^{14}$ A significant association was found between overweight/obesity and smoking status with a prevalence of $75 \%$ among nonsmokers compared to $62 \%$ among smokers. These results were consistent with those of a study conducted on Saudi adults. ${ }^{15}$ These findings might be attributed to the fact that smoking is associated with decreased appetite. The study is primarily limited by having a larger sample of female participants. Since the household visits were made during the day hours, many men members of the households might have been at work. This limitation has possibly increased the overall prevalence of overweight and obesity since the prevalence was significantly higher among female participants.

\section{Conclusion}

The overweight and obesity prevalence in Erbil city is very high. Overweight and obesity were significantly associated with increasing age, female gender, and marital status. This high prevalence requires serious consideration of the health policymakers and public health specialists to plan effective and preventive and control measures so that serious health consequences can be avoided.

\section{Competing interests}

The author declares no competing interests.

\section{References}

1. WHO. Obesity: Preventing and managing the global epidemic. Report of a WHO consultation. WHO Technical Report Series 894. World Health Organization Technical Report Series (Vol. 894). (Accessed November 11, 2017 at http://www.who.int/nutrition/publications/ obesity/WHO_TRS_894/en/).

2. Rizzuto D, Fratiglioni L. Lifestyle factors related to mortality and survival: A mini-review. Gerontology 2014; 60:327-35. 
3. WHO. WHO obesity and overweight fact sheet no 311. (Accessed December 12, 2017 at http://www.who.int/mediacentre/factsheets/fs311/ en/)

4. $\mathrm{Ng} \mathrm{M}$, Fleming $\mathrm{T}$, Robinson $\mathrm{M}$, Thomson $\mathrm{B}$, Graetz N, Margono C, et al. Global, regional, and national prevalence of overweight and obesity in children and adults during 1980-2013: A systematic analysis for the Global Burden of Disease Study 2013. Lancet 2014; 384(9945):766-81.

5. Ogden CL, Carroll MD, Kit BK, Flegal KM. Prevalence of childhood and adult obesity in the United States, 2011-2012. JAMA 2014; 311(8):806-14.

6. WHO. Framework for the implementation of the Global Strategy on Diet, Physical Activity and Health in the Eastern Mediterranean Region. Regional Office for the Eastern Mediterranean. (Accessed October 23, 2017 at http://www.emro.who.int/noncommunicablediseases/summaries/framework-for-theimplementation-of-the-global-strategy-on-dietphysical-activity-and-health-in-the-easternmediterranean-region.html).

7. Xu W, Zhang H, Paillard-Borg S, Zhu H, Qi X, Rizzuto D. Prevalence of overweight and obesity among Chinese adults: Role of adiposity indicators and age. Obesity Facts 2016; 9(1):1728.

8. Speiser PW, Rudolf MCJ, Anhalt $\mathrm{H}$, Camaco-Hubner C, Chiarelli F, Eliakim A,et al. Childhood obesity. J Clin Endocrinol Metab 2005; 90(3):1871-87.

9. Ismael S, Ahmed H, Hasan M. Prevalence of metabolic syndrome in a sample of population in Erbil city, Iraq. Zanco J Med Sci 2016; 20(2):1280 -7 .

10. Mansour AA, Al-Maliky AA, Salih M. Population overweight and obesity trends of eight years in Basrah, Iraq. Epidemiol 2012; 2(1):110.

11. Rahmani A, Sayehmiri K, Asadollahi K, Sarokhani M. Investigation of the prevalence of obesity in Iran: A systematic review and meta-analysis study. Acta Medicalranica 2015; 53(10):596-607.

12. Cuschieri S, Vassallo J, Calleja N, Camilleri R, Borg A, Bonnici G,et al. Prevalence of obesity in Malta. Obes Sci Pract 2016; 2(4):466-70.

13. Ayatollahi SMT, Ghoreshizadeh Z. Prevalence of obesity and overweight among adults in Iran. Obes Rev 2010; 11(5):335-7.

14. Bishwajit G. Household wealth status and overweight and obesity among adult women in Bangladesh and Nepal. Obes Sci Pract 2017; 3(2):85-92.

15. Ginawi IA, Bashir Al, Alreshid $Y Q$, Dirweesh A, Al-Hazimi AM, Ahmed HG, et al. Association between obesity and cigarette smoking: A community-based study. J Clin Endocrinol Metab 2016; 6(5):149-53. 